\title{
Normocaloric versus hypocaloric feeding in ICU patients: response to comments by Bitzani
}

\author{
Paul E. Marik ${ }^{*}$ and Michael H. Hooper
}

C 2016 Springer-Verlag Berlin Heidelberg and ESICM

\section{Dear Editor,}

We thank Dr. Bitzani for her thoughtful letter [1] regarding our initial article [2]. We agree completely that "the issue of optimal nutrition delivery in this patient group is still largely unclear" and therefore believe that it is inappropriate to make strong recommendations regarding the provision of calories and protein in this heterogenous group of patients [3]. It is noteworthy that the mean amount of calories delivered in the "normocaloric" arm of the trophic and permissive underfeeding groups was 1359 and $1246 \mathrm{kcal} /$ day, respectively. It is therefore most unlikely that these patients were overfed, as suggested by Dr. Bitzani. Indeed, some experts have suggested that the failure of these trials to demonstrate a benefit of normocaloric feeding is because the patients in the "normocaloric" arms were underfed. Critical illness is associated with the severe loss of muscle mass which is associated with serious long-term disability $[4,5]$. The excess provision of protein has been directly correlated with the degree of muscle loss [4]. Multiple experimental models and real-life clinical observations have clearly demonstrated that the continuous provision of high doses of amino acids compromise muscle protein synthesis [6]. The recommendation in the current guidelines that "protein requirements are expected to be in the range of $1.2-2.0 \mathrm{~g} / \mathrm{kg} /$ day" [3] is likely to be harmful in critically ill patients (when given as a continuous infusion) [6]. It is important to emphasize that there is no high-quality evidence in critically ill or injured patients that one particular nutritional strategy is associated with better patient outcomes than another. Our approach is quite simple; use the gut, do it slowly, do it intermittently, and use a high-quality formula.

\section{Compliance with ethical standard}

Conflicts of interest

Both authors declare that they have no conflict of interest with regards to the content of this correspondence.

Accepted: 28 January 2016

Published online: 15 February 2016

\section{References}

1. Bitzani M (2016) Comments on: Normocaloric versus hypocaloric feeding on the outcomes of ICU patients: a systematic review and meta-analysis. Intensive Care Med. doi:10.1007/s00134-016-4248-0

2. Marik P, Hooper M (2015) Normocaloric versus hypocaloric feeding on the outcomes of ICU patients: a systematic review and meta-analysis. Intensive Care Med 1-8. doi: 10.1007/s00134-015-4131-4

3. Taylor BE, McClave SA, Martindale RG, Warren MM, Johnson DR, Braunschweig C, McCarthy MS, Davanos E, Rice T, Cresci GA, Gervasio JM, Sacks GS, Roberts PR (2016) Guidelines for the provision and assessment of nutrition support therapy in adult critically ill patient: Society of Critical Care Medicine (SCCM) and American Society of Parenteral and Enteral Nutrition (ASPEN). Crit Care Med 44:390-438

4. Puthucheary ZA, Rawal J, McPhail M, Connolly B, Ratnayake G, Chan P (2013) Acute skeletal muscle wasting in critical illness. JAMA 310:1591-1600

5. Herridge MS, Tansey CM, Matte A, Tomlionson G, Diaz-Granados N, Cooper A, Guest CB, Mazer CD, Mehta A (2011) Functional disability 5 years after acute respiratory distress syndrome. $\mathrm{N}$ Engl J Med 364:1293-1304

6. Marik PE (2015) Feeding critically ill patients the right "whey": thinking outside the box. A personal view. Ann Intensive Care 5:11 